\title{
Construccion de procesos de significacion desde las estrategias expositivas en 1979. Un monumento a instantes radicales
}

Ivonne Viviana Villamil*

\section{Resumen}

A partir del caso de estudio de la exposición 1979, un monumento a instantes radicales, comisariada por Carles Guerra y que tuvo lugar en 2011 en La Virreina Centre de la Imatge en Barcelona, en este artículo se describe el proceso de construcción de los contenidos y los bloques discursivos a través de la selección y el ordenamiento de los materiales que conforman la muestra, mientras se aborda teóricamente el ámbito de los estudios de la cultura visual. De este modo, se resume la experiencia de observación, análisis e interpretación de procesos propios del ámbito de los estudios culturales.

Palabras clave: comisariado de exposiciones, display expositivo, estudios culturales, La Virreina Centre de la Imatge, narrativas visuales

\section{Abstract}

A case study, the exhibition: 1979, a monument to radical instants curated by Carles Guerra took place in 2011 at La Virreina Center de la Imatge in Barcelona. This article describes the process behind the contents and discursive chapters through the selection and order of the materials that make the exhibition, at the same time; a close analysis of visual culture studies. In this way the experience of observation, analysis and interpretation of processes specific to the field of cultural studies is summarized trough this case study.

Keywords: cultural studies, curating exhibition, exhibition display, La Virreina Centro de la Imatge, visual narratives

\footnotetext{
* Master en Artes Visuales y Educación de la Universidad de Barcelona. Líder de investigación en el programa de Comunicación Social de la Corporación Unificada de Educación Superior (cuN). Contacto: ivonne_villamil@cun.edu.co
} 


\section{Introducción}

En este texto se plantea como campo de estudio el proceso de construcción del discurso mediante las estrategias expositivas, entendidas como el conjunto de decisiones y acciones que se ejercen sobre el material y el espacio expositivo. El análisis de algunos momentos de la exposición 1979. Un monumento a instantes radicales ${ }^{1}$, por ejemplo el "Walkman de Sony", dará cuenta del uso de estas estrategias que, revisadas desde las condiciones y mecanismos de su visualización, permitirán repensar el ámbito expositivo como herramienta de aprendizaje y de significación, desde una perspectiva de la cultura visual²:

Exhibitions are the primary site of exchange in the political economy of art, where signification is constructed, maintained and occasionally deconstructed. Part spectacle, part socio-historical event, part structuring device, exhibitions -especially exhibitions of contemporary art- establish and administer the cultural meanings of art. (Greenberg, Ferguson y Nairne, 1996, p. 2)

La relación que aquí se establece entre los diferentes temas nace de un interés teórico por el terreno de los estudios sobre museos y las prácticas comisariales en concordancia con la cultura visual; motivo por el cual, el texto indaga acerca del papel, la implicación y las posibilidades de estas prácticas en procesos de codificación, producción y circulación de los contenidos culturales.

A través del señalamiento de ejemplos concretos de 1979. Un monumento a instantes radicales se reflexiona sobre los campos de estudio desde el diálogo con autores y la descripción de situaciones de encuentro con la exposición que, en sí misma, remite a temas de análisis más amplios; por ejemplo, el uso del display ${ }^{3}$ como herramienta discursiva y las localizaciones conceptuales como lugar de resignificación. Al situar el debate en un terreno que va más allá del encuentro casual con las obras o las exposiciones, se abordan de manera críticoreflexiva las dinámicas de instauración de determinadas formas de visualidad o "formas de encuadre" (Bal, 2003, p. 16) que intervienen en los procesos de producción de los contenidos. ¿Bajo qué condiciones experimentamos y percibimos los artefactos culturales? ¿Cuáles son las implicaciones de la mediación especializada que supone tanto la labor del comisario como de la institución, que es la encargada de hacer públicos estos contenidos? ¿Cómo están determinados estos procesos de codificación y qué estrategias expositivas se utilizan para la materialización del discurso?

Las características y contextos de los casos también proporcionan herramientas relevantes

1 Esta exposición se presentó entre el 11 de marzo del 2011 y el 12 de junio del 2011 en La Virreina Centre de la Imatge (Barcelona).

2 En relación con el objeto de la cultura visual, en su artículo "El esencialismo visual y el objeto de los estudios visuales", Bal afirma que "una posible aproximación sería la que concede atención a las diferentes formas de encuadre no sólo del objeto sino también del mismo acto de contemplarla [...]. Si la lectura de los objetos incluye a lo social, a la gente, su estudio incluiría también a las prácticas visuales posibles dentro de una cultura particular y, por tanto, dentro de regímenes escópicos o visuales; incluiría en definitiva a toda forma de visualidad" (2003, p. 16).

3 En este punto se entiende el display no solo como el acto de mostrar o exhibir, sino también como el conjunto de estrategias, condiciones y mecanismos expositivos a través de los cuales se visualizan y experimentan las exposiciones. 
para su análisis. La Virreina Centre de la Imatge, en sus líneas de acción, propone reflexionar sobre las dinámicas de producción y circulación de las imágenes y la cultura, lo que al mismo tiempo promueve la reflexión crítica sobre el establecimiento de políticas institucionales y culturales. La exposición, por su parte, al responder al formato de exposición de tesis en cuanto materialización de la investigación comisarial, propone una narrativa estructurada desde bloques discursivos que se establecen como capítulos para abordar los ejes temáticos que albergan los contenidos: la estética de la resistencia, revoluciones, instituciones y sala de documentación, configurados a partir de materiales heterogéneos, en diálogo, que coexisten dentro de un mismo espacio de significación como se puede observar en la distribución del plano de sala de la exposición (figura 1$)^{4}$.

Figura 1. Plano de la exposición 1979. Un monumento a instantes radicales (planta 2)

[VIRЯEINA / EXP]

PLANTA 2A

[S1]

LA ESTÉTICA

DE LA RESISTENCIA

[S2]

REVOLUCIONES

[S3]

SALA DE DOCUMENTACIÓN

[SXM]

INSTITUCIONES

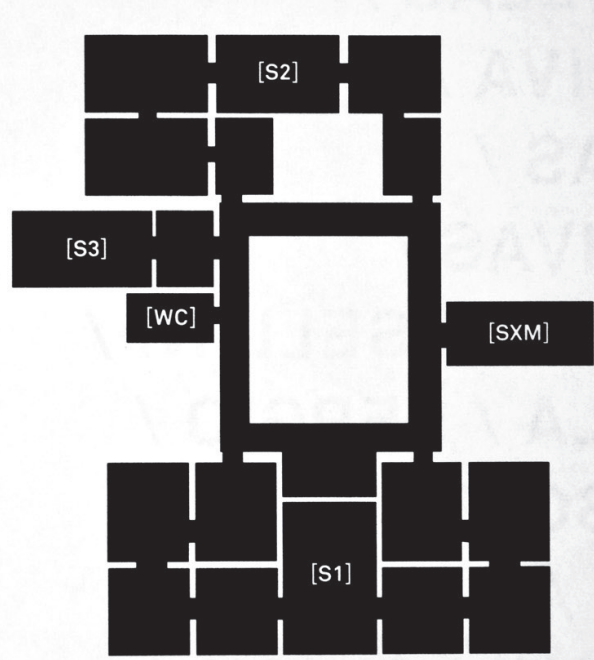

Fuente: La Virreina Centre de la Imatge (2011, p. 2).

A través de la exposición y de la pieza que se estudia en este contexto, el "Walkman de Sony", se evalúan las temáticas al profundizar en las condiciones particulares de las estrategias narrativas que las configuran, el proceso de construcción de su significado desde los esquemas de interpretación sugeridos en la disposición expositiva y el diálogo con los contenidos de las otras piezas y los demás bloques discursivos. Pero, ¿por qué este caso es relevante a la hora de reflexionar sobre los mecanismos de significación? ¿Cómo podemos inscribir esta exposición en el ámbito de los estudios sobre cultura visual y cuál es su aporte a este? 
Esta investigación propone posibles vías de diálogo en torno a las implicaciones que conlleva la generación de formas de visualidad desde la práctica expositiva. Las piezas, a su vez, se pueden estudiar como componentes discursivos que hacen parte de la narrativa (discursiva y visual), estructurada también desde esta práctica:

Los contextos proporcionan las conexiones culturales que hacen que valga la pena estudiar imágenes y objetos, y es una parte de la obra de arte tanto como la forma, la función o el significado simbólico. Es un tipo de narrativa relacionada sin rigidez al objeto físico,

\section{Reposicionamientos y perspectivas}

Si nos detenemos un instante a pensar en los actos de visión a los que se refiere Bal, podemos abordar correctamente esta idea desde un primer momento en el que los actos de visión tienen lugar o desde los procesos que producen el régimen de visualidad que posibilita los actos, como respuesta a esta construcción.

En lugar de la visualidad como propiedad característica y definitoria de los objetos, son los actos de visión hacia esos objetos los que constituyen el objeto de su dominio: su historicidad, su anclaje social y la posibilidad de análisis de su sinestesia. Es en la facultad para realizar actos de visión, y no en la materialidad del objeto contemplado, donde se decide si un artefacto puede ser considerado desde la perspectiva de los estudios de la cultura visual. (Bal, 2003, p. 20) como una historia retratada por su imagen $[. .$.$] . Como resultado, en nuevos$ contextos, las respuestas a la cultura visual no sólo se forman, se transforman.

(Freedman, 2006, p. 82)

De acuerdo a esta perspectiva, se plantea la revisión del hecho expositivo como contexto, como herramienta para relacionarnos con el mundo a través de las imágenes y los objetos, a la vez que se reflexiona acerca de estos mecanismos para potenciar de manera consciente su función como generadores de procesos de aprendizaje desde la transmisión, interpretación y significación de los artefactos culturales.

En el texto, se asumen los proyectos expositivos como estructuras generadoras de actos de visión que implican la historicidad y el anclaje social como facultad para realizar actos de visión y que, más allá del acto sensorial de ver, supone la visión como capacidad interpretativa, de puesta en relación y de significación.

Por el tipo de narrativa que propone (vinculada con la historia, con fenómenos sociales, culturales y con acontecimientos simultáneos en lugares y tiempos dispares), 1979. Un monumento a instantes radicales resulta un buen punto de partida para estudiar estos actos y su relación con las estrategias expositivas. El discurso de la exposición está claramente anclado a referentes de la historia como las guerras civiles, las revoluciones, la biopolítica o el posfordismo. Pero su interpretación comprende también el hecho de que el espectador está en un tiempoespacio particular desde el que percibe $y$ reinterpreta este discurso que se traduce en 
formato visual, a través de documentos, material de archivo, fotografías, objetos, entre otras piezas que conforman el recorrido. Es decir, la exposición propone el año 1979 como un punto de inflexión, de transición, que debe ser revisado desde los acontecimientos que tuvieron lugar en ese año. Ahora bien, a este planteamiento subyace la idea de que esta revisión se hace desde la distancia crítica del hecho histórico, lo que implica un marco para esta lectura que incide directamente en las relaciones que establecemos y en el tipo de discurso que construimos desde la interpretación en el momento de mirar.

"Puesto que ver es un acto de interpretación, puede influir sobre las formas de ver, y por tanto, de imaginar posibilidades de cambio" (Bal, 2003, p. 20), el hecho expositivo no debe asumirse como fenómeno aislado, sino como vehículo de construcción de formas de visualidad y de significación. En este sentido, nos sitúa no solo ante imágenes, sino también ante contenidos, vínculos y lecturas de hechos históricos, políticos y sociales reformulados desde determinadas perspectivas; en este caso, desde la perspectiva de la investigación comisarial que toma forma a través de la exposición. Así, visto desde las dinámicas de la cultura visual, su implicación trasciende el mero hecho, pues torna en un acto de interpretación que establece conexiones culturales más amplias, que producen procesos de encuentro, relación y cognición.

Fernando Hernández, en el marco del seminario sobre Pedagogías de la Cultura Visual, decía que la hegemonía de lo estético no es del arte, la estética está en la vida, por tanto, no se puede escapar de la vida. En el desarrollo de este texto, lo estético sigue siendo considerado desde el análisis de una muestra de arte contemporáneo, pero no se limita al campo del arte, sino que aborda los cruces con una multiplicidad de lugares y ámbitos, algunos propuestos por el comisario a manera de reescritura de la historia, otros encontrados desde el acto de la interpretación. La estética está en la vida social, en la cultura, en los acontecimientos y en los referentes políticos que dialogan con un momento específico (1979 en este caso) que sirve como punto de partida para dirigir la mirada en busca de nuevas construcciones de la historia.

Cualquier decisión que tomamos desde el campo de la educación en artes es una decisión política porque influye en la construcción de sujetos. Asimismo, exponer es una forma de promover y gestionar el conocimiento, es una acción política en tanto construye también los contenidos que la cultura transmite. Por esto, la exposición es un acto que se debe reflexionar, así como la práctica y las responsabilidades que esta implica en la construcción de conocimiento:

Rather, it suggests that each moment of interpretation holds within it a potential for interpretation that may not have been co-present with the event, image, or cultural practice at its moment of production. It also suggest that meaning is in part contingent on the conditions of the encounter in which works of art both articulate with their own histories of making and anticipate practices of reading which are not thereby confined. The effect of the work is to create, possibly belatedly, terms of analysis that are constantly renewing the active semiotic productivity of the work. (Pollock, 2006, p. 15)

Estas conexiones permiten una evolución desde el primer acercamiento a los objetos, imágenes y materiales que conforman la exposición, hasta el análisis de la red de procesos que estructuran 
el régimen de visualidad que se propone a través del montaje ${ }^{5}$, al codificar y determinar la mayoría de los actos de visión que suceden durante la producción y recepción del discurso. Como señala Pollock, el significado depende, en parte, de las condiciones en las que se produce este encuentro, condiciones que es necesario estudiar a partir de la estructura expositiva de 1979. Un monumento a instantes radicales, desde los instantes de interpretación que esta produce y posibilita:
La cuestión es sencilla: ¿qué sucede cuando la gente mira y que acaece de tal acto? El verbo "suceder" se referiría aquí al evento visual como objeto, y "acaece" a la imagen visual pero como una imagen que es fugaz, fugitiva, subjetiva y que corresponde al sujeto. Estos dos resultados -el evento y la imagen experimentada- se unen en el acto de mirar y las consecuencias que este implica. (Bal, 2009, pp. 16-17)

\section{La exposición como proceso de investigación: 1979. Un monumento a instantes radicales}

En el programa de mano de 1979. Un monumento a instantes radicales se afirma que

entre 1968 y 1989, hay 1979, un año cualquiera. Nada indica en principio, que esta fecha sea más relevante que otras. Sin embargo, al recopilar algunos de los acontecimientos de aquel año, enseguida emerge una constelación de hechos, obras, datos, textos, imágenes, películas, canciones y objetos que, a pesar de que en un primer momento no parecen compartir más que la fecha, sugieren muy pronto una inflexión histórica [...]. La exposición se plantea como un ensayo histórico que evita una imagen compacta de aquel año. Por el contrario, busca representar la heterogeneidad de los acontecimientos comprendidos, como si la historia una vez revisada todavía pudiese sugerir una multiplicidad de direcciones y líneas de desarrollo. (La Virreina Centre de la Imatge, 2011, párr. 1)

Carles Guerra (comisario de la exposición), en el marco de una visita comentada, afirmaba que esta era "difícil de cerrar en su recorrido". Esto tiene sentido si se tiene en cuenta que está estructurada en la novela La estética de la resistencia ${ }^{6}$, en la que su autor, Peter Weiss, "sitúa la acción entre 1937 y 1945, transitando de la Guerra Civil española a la Segunda Guerra Mundial" (La Virreina Centre de la Imatge, 2011, párr .3). Weiss accede a estos acontecimientos solo a través de documentos históricos, relatos, imágenes, cuadernos y diarios; entonces, podríamos decir que este hecho privilegia la interpretación como elemento determinante en la construcción narrativa, de forma tal que la novela resulta ser

5 “El montaje es en principio un término perteneciente al terreno audiovisual, pero como concepto ampliado, ¿no posibilitaría acaso revisar los sistemas de relación presentes en ámbitos como las producciones culturales o la cultura visual, bajo la consigna de su definición como ordenación narrativa coherente a las dinámicas de un relato? Es un truco, es cierto, una herramienta de maquillaje, de ficción, pero también de elucubración, de articulación y construcción de discursos" (Villamil, 2011, parr. 1).

6 La estética de la resistencia es una novela publicada en tres volúmenes entre 1975 y 1981. 
"un momento literario edificado sobre un mar de documentación” (párr. 3).

“El espacio de la exposición se entiende pues como un lugar dinámico y complejo, del mismo modo que el espacio de las conexiones ideológicas y vitales que Peter Weiss nos describía en $L a$ estética de la resistencia" (párr. 8). Este modelo interpretativo, o creativo si se quiere, se traspasa a la estructura expositiva al seguir la idea de Weiss a la que Guerra constantemente hacía alusión, cuando se refería a la acumulación como proceso de conectividad: "en la medida en que pueda meter el mundo en una caja podré describirlo". La exposición, propuesta como un ejercicio de historia, estructura un sistema de relaciones, como bien lo ilustra la imagen de Philippe Van Snick que aparece como metáfora del recorrido (figura 2). Materiales dispares y heterogéneos vinculados a través de conexiones que suceden, algunas veces, por mera coexistencia, y otras, por elaborados diálogos construidos mediante estrategias expositivas.

Figura 2. Duiven

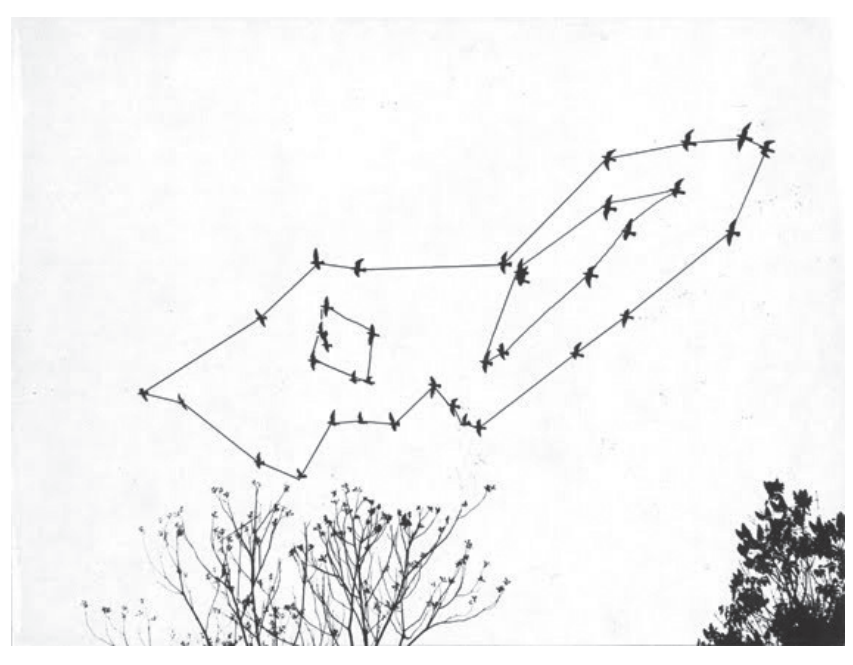

Fuente: Snick (2010, p. 55).

Si 1979 aspira a convertirse en un monumento a instantes radicales, sólo puede hacerlo entendiéndose como uno de aquellos dibujos para niños en los que hay que unir y enlazar puntos numerados hasta que emerge una forma desconocida. A partir de una confusión inicial puede avanzarse, poco a poco, hacia una gestalt. Entonces puede descubrirse una forma latente que antes no era perceptible. Los trazos entre punto y punto dan una forma definitiva a lo que había frente de nosotros sin que lo pudiésemos reconocer. (La Virreina

Centre de la Imatge, 2011, párr. 9)

Las relaciones elaboradas o inesperadas, la acumulación y la descripción detallada de acontecimientos en momentos y lugares diversos, configuran la propuesta del comisario, quien revisa un año cualquiera para resignificarlo como momento de transición, como hecho histórico reformulado desde la selección de conexiones que marcan un punto desde el cual repiensa la historia. Este punto es la confluencia 
de los instantes acumulados mediante el buscando asociaciones entre elementos material expositivo, mientras configura el espacio atemporal o multitemporal, y que puede ser leído como un punto de vista de la historia o como el lugar desde el cual situarnos para mirarla.

Hay una fotografía de Weiss en la que se nos presenta ante un inmenso archivo con multitud de cajones abiertos [figura 3]. Con este material, hecho de imágenes, documentos, testimonios, escribió su Estética de la resistencia, dispares y argumentando su manera de ver el mundo en un contexto de complejidad social y política. También Carles Guerra despliega su subjetivo archivo -con sus fetiches y obsesiones- con la voluntad de construir una memoria o un imaginario. En 1979, Guerra tenía 14 años. Puede que la exposición sea su particular crónica sentimental o que su propuesta se exprese en los términos políticamente correctos que se exigen hoy en día. (Vidal, 29 de abril de 2011, párr. 4)

Figura 3. Peter Weiss consultando su archivo

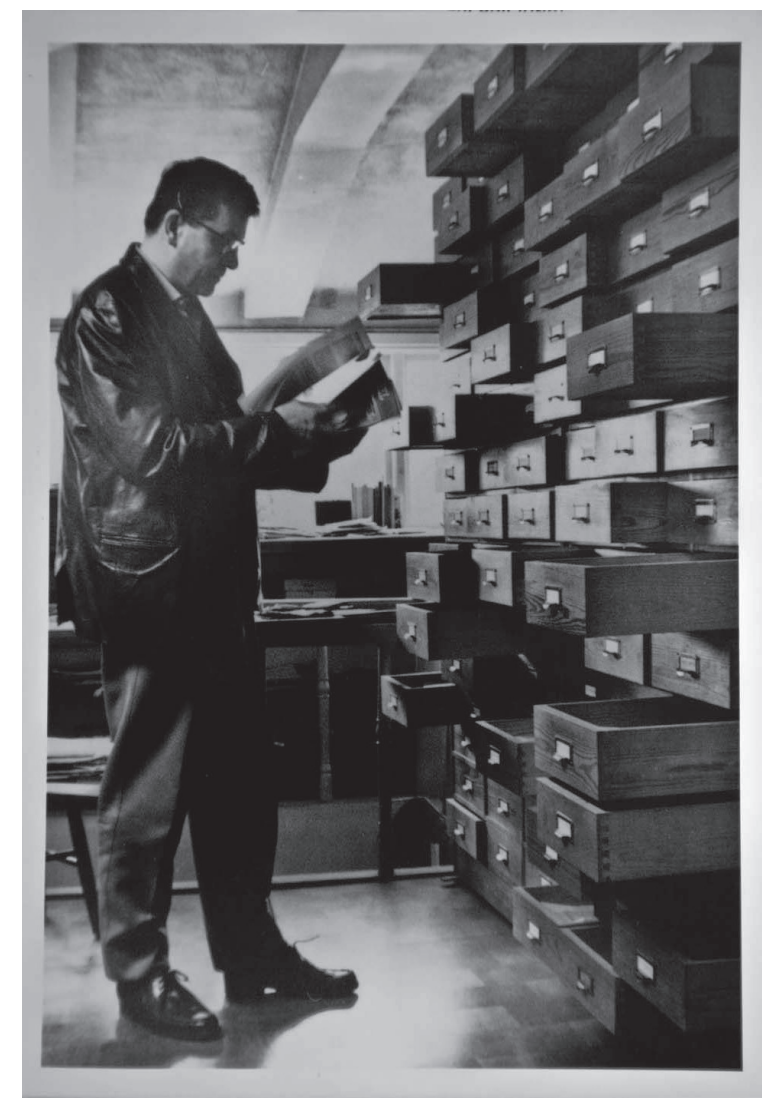

Fuente: postal de la exposición, archivo personal de la autora (2011). 
En lugar de avanzar hacia una gestalt, propondría que se avanza hacia múltiples y diversas construcciones de gestalt, ya que se pueden establecer algunas de las relaciones entre las piezas o ubicarnos momentáneamente en uno de los espacios-tiempos propuestos para revisar la historia; pero no sería posible afirmar que, de manera definitiva, el público accede a este discurso expositivo como un único constructo de relaciones establecidas. Es decir, a través del encuentro con las piezas se producen localizaciones desde las que asumir la lectura de los contenidos, pero el discurso conceptualizado -tal y como es concebido por su comisario- y las formas de interpretación a través de las cuales producimos los significados no se corresponden necesariamente al primer encuentro con la exposición, debido a la complejidad que representa el propio discurso.

The ordering of artefacts, but also the spatial configuration of museum rooms and their respective codes of behavior

\section{Economía de acceso a las imágenes}

A través de la acumulación de imágenes y objetos de instantes relacionados con el año 1979, este se monumentaliza como un año de cambios y transiciones. El material va ilustrando una serie de relaciones de significado que, en primera instancia, no parecen ni obvias ni determinadas y que provienen de un ejercicio de historias sincrónicas que se conectan por su coexistencia y por el discurso que propone el comisario en su proyecto.

A partir de la idea planteada por Bal, en la que el artefacto puede ser considerado desde una perspectiva de los estudios de cultura visual, are to be read as texts that are subject to analysis and deconstruction, by drawing on Michel Foucault's notion of discourse. Their economies, their gender and "ethnifying" codes, as well as the historical and social conditions of their emergence are analyzed. Seen from this perspective, exhibitions and their institutions generate - through an interplay of historical antecedents, behavioral norms, and curatorial staging - rites or so -called "civilizing rituals" that induce subjects to conform, as well as quasi-mythical narratives the adhere to a hegemonic patriarchal, and colonial historiography. In the 1980s, these readings converged in the field of new museology under the call to incorporate subject positions and discourses so far excluded and to produce so-called "counternarratives", thereby turning the museum into a space of interaction and exchange. (Mörsch, 2009, p. 17)

no en su materialidad como objeto sino en la "facultad para realizar actos de visión" (2003, p. 20), quisiera aludir a una metodología que se evidencia en el recorrido por la exposición y que el comisario Carles Guerra llamaba "economía de acceso a las imágenes". Los microacontecimientos que la conforman están situados dentro del discurso, como mencionaba anteriormente, mediante una serie de materiales heterogéneos que, por supuesto, no están compuestos solamente por obras de arte. Pero lo importante en este punto es que la forma de acceso a estas imágenes por parte del comisario permite la coexistencia dentro del mismo 
recorrido de piezas tan dispares, por ejemplo objetos comprados por e-bay -el caso del poster de "Apocalypse Now" o el "Walkman de Sony"-, una selección de documentos de Peter Weiss en préstamo de La Akademie der Künste de Berlín y del Deutsches Historisches Museum de Berlín, instituciones que también cedieron la imponente pintura "La Huelga" (1886) de Robert Koehler, entre otras piezas que conforman la muestra.
Esta decisión comisarial, que propone las imágenes desde sus posibilidades de acceso, puede considerarse, como mencionaba Guerra: otro tipo de estética desde la que acceder a los acontecimientos, estética que responde a la necesidad de la construcción del discurso.

Figura 4. Fotografías del montaje de las piezas en la exposición

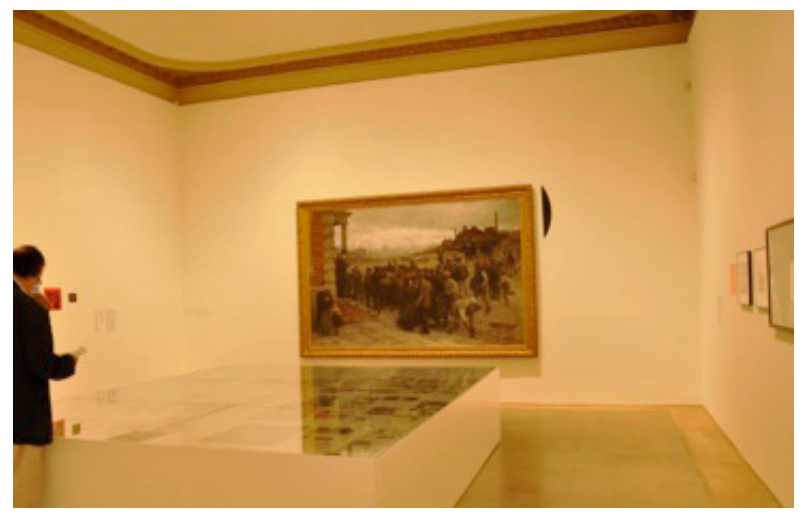

Fuente: archivo personal de la autora (2011).

Los diálogos con las obras, objetos e imágenes se generan en la medida en que es posible tener encuentros con estas; así, la manera en que dialogamos incluye, por supuesto, la forma en que accedemos a este encuentro, a través de qué medios las conocemos y bajo qué condiciones las experimentamos. ¿No podría considerarse esta idea una vía para problematizar también la forma en que accedemos a la cultura misma?

La idea constante en el proyecto de no generar un ícono único que represente este año, sino concebirlo como una multiplicidad de

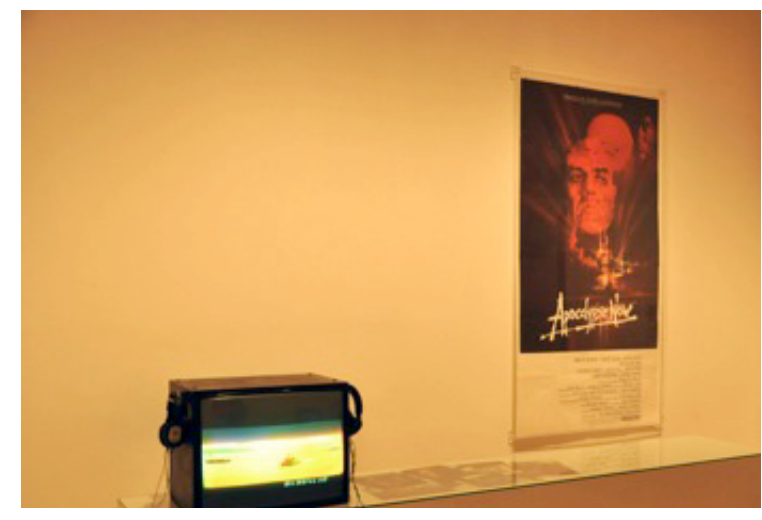

acontecimientos, como una suma de momentos, encuentra también eco en esta metodología que no concibe las piezas del recorrido como master pieces sino como formas múltiples y heterogéneas desde las que se accede a tales instantes. La alternativa metodológica prioriza en las necesidades a la hora de representar de manera visual el discurso e, incluso, al resaltar el carácter no original de algunas piezas, nos ofrece formas de acceder a los contenidos de las imágenes desde la apropiación de los significados y la presentación -o reproducciónbajo los parámetros de esta economía. 


\section{'Making sense of the Walkman'}

En la exposición 1979. Un monumento a instantes radicales el "Walkman de Sony" aparece dentro del espacio llamado "Sala de documentación". Al entrar en esta sala, se encuentran dos obras que cuestionan el cambio de paradigma sobre la percepción: Brugaters $i$ algòlegs de Perejaume, reúne en una vitrina unas gafas de buceo con visera y las imágenes que dan cuenta de la acción del artista en 1980, cuando tras, sumergirse para observar el paisaje marino, baja la visera y la sube nuevamente en frente de una montaña y verificar como realidades contiguas ambas vegetaciones: las algas y el paisaje montañoso.

Figura 5. Fotografías de las obras: Brugaters i alogers de Perejaume y March 5 th 1979 de Patricia Daúder

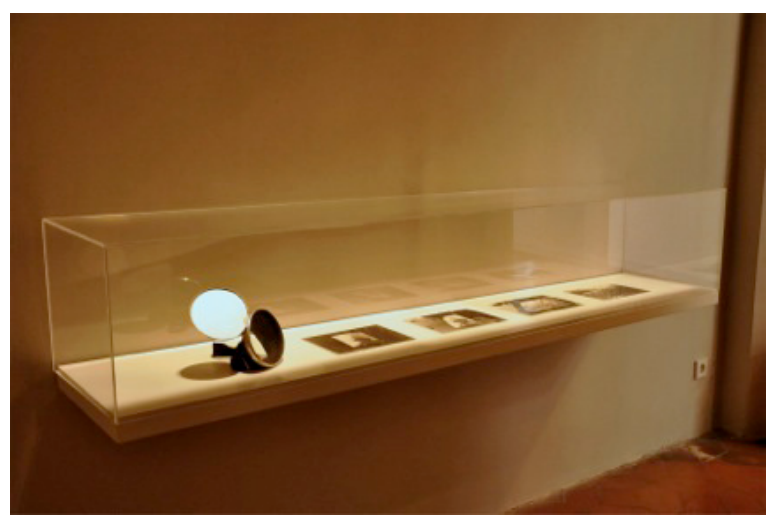

Fuente: archivo personal de la autora (2011).

En seguida, la película en $16 \mathrm{~mm}$ de Patricia Daúder recoge imágenes que han circulado del fenómeno luminoso del 5 de marzo de 1979 sobre el archipiélago canario, que hasta hace pocos años fue considerado como un avistamiento de ovnis hasta que se aclaró que había sido causado

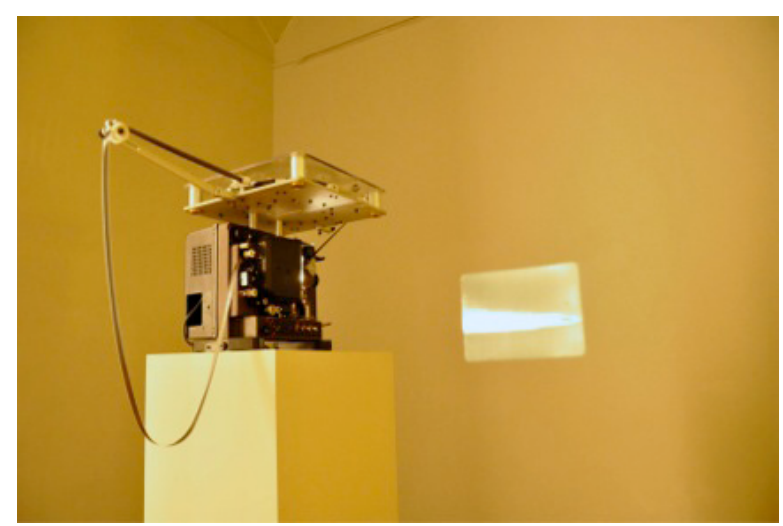

por el lanzamiento de unos misiles desde un submarino norteamericano. Así, March 5th 1979 se construyó a partir de fotografías tomadas por los isleños que creían estar ante la presencia de un avistamiento. 
Figura 6. Fotografía del Walkman de Sony. Da cuenta de la forma en que se exponía en 1979. Un monumento a instantes radicales

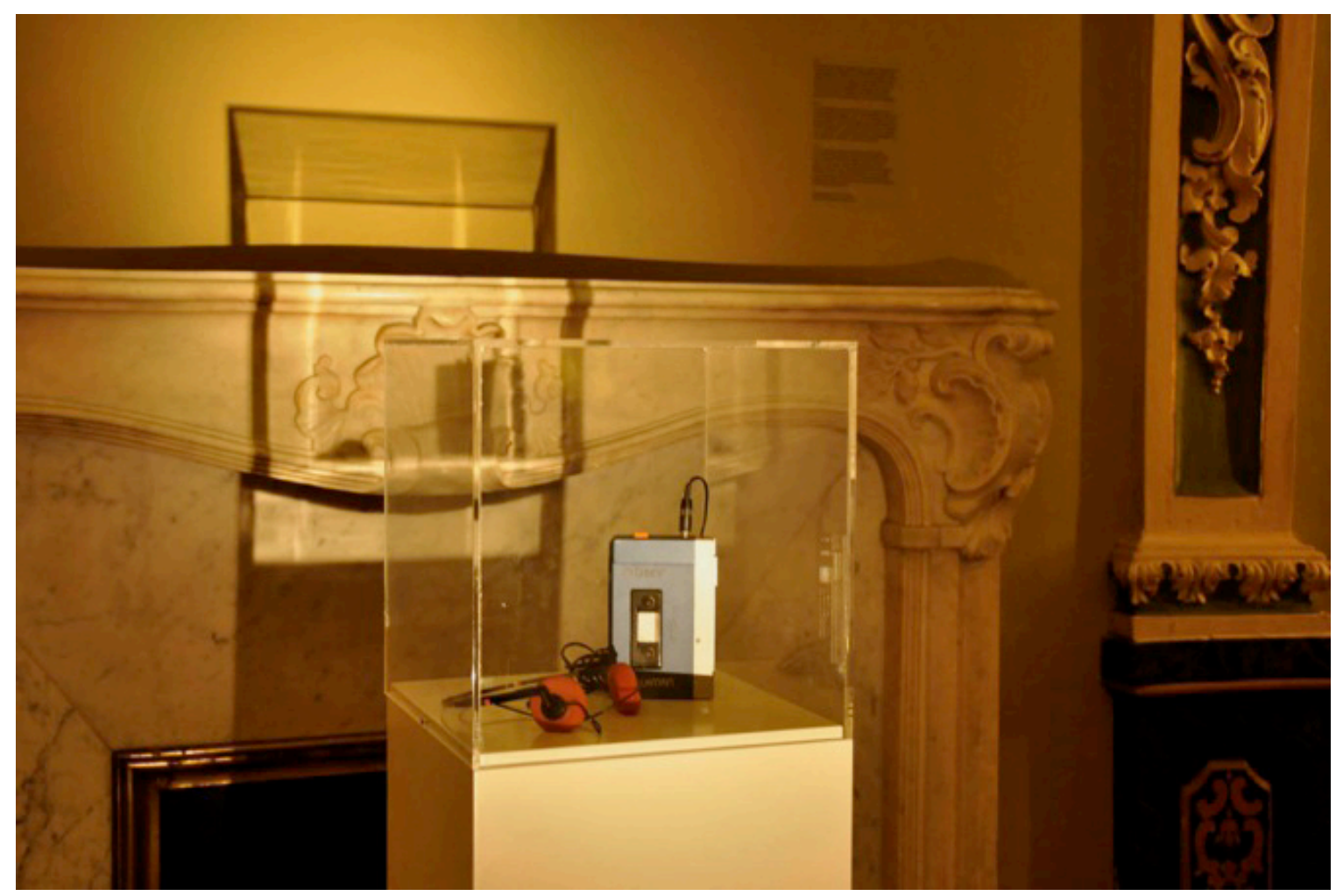

Fuente: archivo personal de la autora (2011).

Luego, dentro del salón, hay una serie de pantallas con auriculares, en donde se puede observar el material documental y unas estanterías con material impreso, revistas y libros, también producidos o relacionados con 1979. Al final, enfrente de una chimenea -que da cuenta de la particular arquitectura de la sala-, en una urna de cristal sobre un módulo de madera, se encuentra el Walkman de Sony (con los clásicos auriculares naranja). En esta configuración el objeto se propone como el cierre del bloque discursivo relacionado con los cambios de paradigma en la percepción y del recorrido de la segunda planta de la exposición, en el que se puede leer el año 1979 como un año de transición, de cambio, en el que uno de los micro-acontecimientos sucede con el Walkman de Sony y con las prácticas culturales y sociales que este genera. Se altera la forma en la que el individuo percibe el mundo al salir a la calle con los oídos tapados, tal y como se altera en la obra de Perejaume a través de la visión. 
Figura 7. Fotografía de la "Sala de documentación"

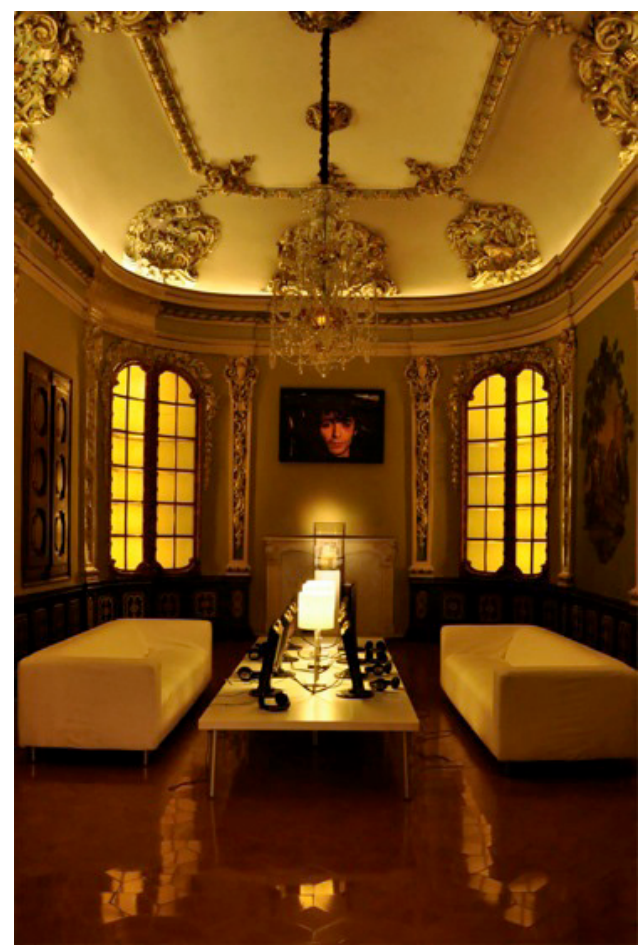

Fuente: archivo personal de la autora (2011).

La estrategia de montaje utilizada en la visualización del objeto exige su contemplación. Pareciera que el cristal legitima su concepción como artefacto cultural, codificándolo desde un lenguaje propio del museo, como sucede con la urna y la disposición del objeto como joya.

Clifford, en su estudio sobre cuatro museos de la costa noroccidental, analiza cuatro contextos diferentes para objetos similares, se describe la forma en que son expuestos y significados en cada caso. En este texto menciona: "he dicho que uno de los modos actuales más efectivos de brindar valor de cruce cultural (moral y comercial) a una producción cultural es tratarla como arte" (1999, p. 147). En este caso nos referimos a su idea, aunque no estamos ante un objeto que responda inicialmente a la categoría de producción cultural, pero que está enmarcado en la cultura visual desde el tratamiento que se le da "como arte". Este hecho permite anular la función primaria del objeto, al estar aislado y expuesto como pieza de "museo", lo priva de ser un objeto funcional en el sentido de uso (como walkman), para otorgarle funciones simbólicas que lo anclan en las políticas que enmarcan los artefactos culturales y las plataformas de construcción y visibilidad de los contenidos.

"Making sense of the Walkman" es el primer capítulo del libro Doing Cultural Studies: The Story of the Sony Walkman, en el que se revisan las prácticas culturales y los procesos de significación a través de cinco procesos culturales: representación, identidad, regulación, consumo y producción. 
Figura 8. There's a revolution in the streets.

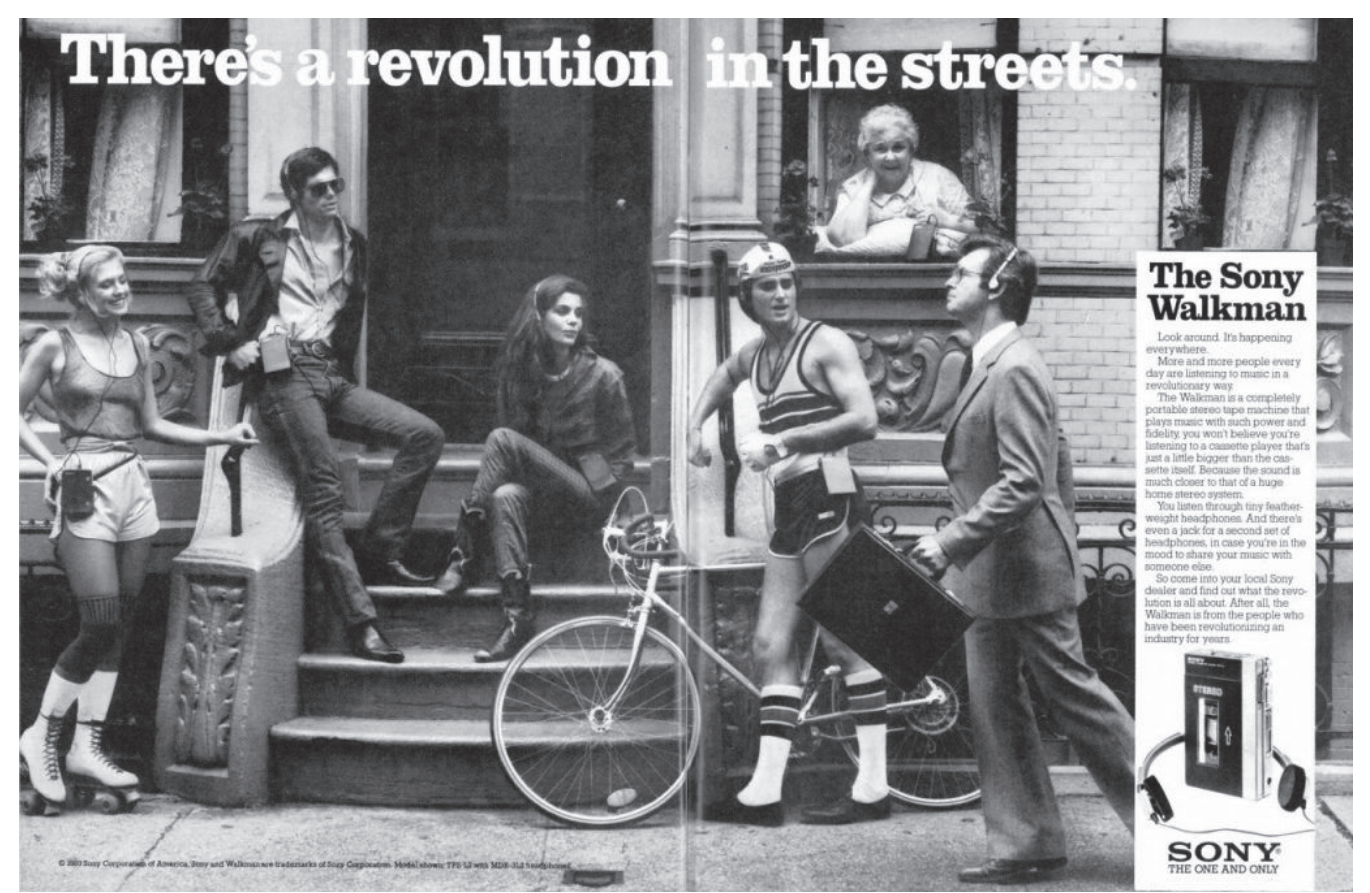

Fuente: Alforova, s. f.

De este libro, además, se resalta el siguiente fragmento:

Culture, then, is inextricably connected with the role of meanings in society. It is what enables us to 'make sense' of things. But how does this 'meaning-making' work? Partly, we give things meaning by the way we represent them, and the principal means of representation in culture is language. By language, we do not only mean language in the strict sense of written or spoken words [...]. Language is the use of a set of signs or a signifying system to represent things and exchange meaning about them.

We can see this process of meaning-construction at work if we think of the moment in 1979 before what we now know as the Walkman existed. How were journalists able to 'make sense' of something they had never seen before? Just looking at the device would not help, for the machine could not speak or explain itself. It did not possess, and could not express, its own intrinsic meaning. Meaning is constructed -given, produced - through cultural practices; it is not simply 'found' in things. (Du Gay, Hall, Janes, Madsen, Mackay y Negus, 1997, pp. 13-14)

Esta revisión sitúa al Walkman como un artefacto cultural y por ende como objeto que debe reflexionarse desde las prácticas culturales. En este sentido, cuando el texto se refiere al lenguaje como término ampliado, como conjunto o sistema de significación, de representación e intercambio de significados, podemos introducir para este estudio la estructura expositiva como lenguaje, por ser además, una vía a través de la cual se representa y da sentido. 
En primer lugar, la exposición: “1979. Un monumento a instantes radicales", en un centro de arte: la Virreina Centre de la Imatge, que hace parte de la administración pública: Ajuntament de Barcelona y que además está ubicada en la "turísticamente transitada" rambla, está enmarcada con unas condiciones y contextos de producción que vienen dadas desde su institucionalización. La cultura instaura, modifica o deconstruye los significados sociales de los artefactos, pero además, es necesario considerar también que la cultura como forma de visualización, influye en la lectura de los contenidos incluso antes del momento de encuentro con estos.

En segundo lugar, cuando se revisan los objetos desde los estudios culturales, el significado no es inherente a estos sino que viene establecido, tanto desde las prácticas culturales como desde las formas en que los públicos construyen sus propios significados y esto implica a su vez, considerar el papel de los regímenes de visibilidad a través de los cuales se experimentan estas relaciones.

\section{Consideraciones finales: El display y el "enmarcado" como vías de experimentación y estrategias expositivas}

Barker examina aspectos relacionados con las prácticas expositivas y los efectos del display en la percepción y en la forma de entender los artefactos culturales, atendiendo de manera especial a temas relacionados con la institución como mediadora de esta experiencia. "It can also, however, be seen in terms of the phenomenon that Marlaux called Metamorphosis: that is to say, the quasimagical transformation of objects into art" (Barker, 1999, p. 12). Luego, el autor señala

However, display itself is just as much an issue here as art. We can put this in focus by nothing that display is a verb as well as noun, active as well as passive: the point being that display is always produced by curators, designers, etc. As such, it is necessarily informed by definite aims and assumptions and evokes some larger meaning

\begin{abstract}
or deeper reality beyond the individual works in the display. In short, it is a form of representation as well as mode of representation. (p. 13)
\end{abstract}

Esta transformación, en el caso del Walkman de Sony, focaliza la reflexión en el sistema mediante el cual el objeto Walkman -comprado por e-bay- aparece codificado a través del lenguaje expositivo y presentado como artefacto cultural.

Así, exponer es necesariamente una acción ideológica que posiciona al discurso y a las imágenes, codificando los contenidos mediante la puesta en diálogo con el objeto mismo, sus relaciones posibles eincluso con las experiencias del espectador. La exposición es la forma que adopta el acto de volver "visible" un discurso. Entonces, analizar las situaciones y condiciones 
que suceden en el proceso de materialización de la exposición 1979 posibilita pensar en los efectos y consecuencias de los actos de mediación que se producen -comisariales, institucionales- y en los objetivos e implicaciones de esta mediación en la producción del discurso.

Sin embargo, el acto de enmarcar produce un acontecimiento. Por encima de todo, esta forma verbal, tan importante como el nombre que indica su producto, es una actividad: algo que realiza un agente responsable de sus actos, a quien podemos pedir cuentas [...]. Si la mise-en-scène es lo que vemos, el enmarcado es aquello que acontece antes de que se presente el espectáculo. (Bal, 2009, pp. 178-180)

Sobre el uso del display y el concepto de enmarcado que propone Bal podríamos conectar con el caso de estudio propuesto, sugiriendo que el acto que se produce a través de las estrategias expositivas que dan forma a 1979, convierte las piezas y el material en eslabones dentro de los bloques discursivos que "traducen" el guion a formato expositivo. El Walkman de Sony es escenificado como artefacto cultural, y el enmarcado como acontecimiento, se produce cuando el objeto se pone en diálogo con su vida social y cultural, con las localizaciones históricas de un pasado al que pertenece y el presente de una distancia crítica desde la que está siendo revisado, es decir, cuando se inscribe en la construcción discursiva del proyecto que se materializa de manera visual.

Pero la pregunta en este punto sería si el mismo enmarcado del "Walkman de Sony" da cuenta de las relaciones con las que conecta. ¿Se logran comprender a través del recorrido las conexiones del objeto con su vida social y cultural, por ejemplo, en tanto símbolo del cambio de percepción del mundo? Esta pregunta, si bien sugiere pensar en los límites y los alcances de las prácticas comisariales, se refiere también a puntos comunes en relación al formato expositivo. Por ejemplo, la relación entre el constructo teórico-investigativo que propone en sus contenidos 1979 y el formato visual, la correspondencia en cuanto lenguajes (texto-imagen) que transitan de un terreno al otro, exigiendo un acto de lectura y en el que los contenidos se visibilizan mediante una estética de la acumulación y la interconectividad.

\begin{abstract}
It analyzes the functions of (authorized and unauthorized) speech and the use of different linguistic registers in the exhibition space. Together with those who participate in gallery education, it attempts to generate counternarratives and thus to disrupt the dominant narratives of the exhibiting institution. But it avoids turning these counternarratives into new master narratives fueled by identity politics. Recipients are not regarded as subordinate to institutional order; rather, the focus is directed at their possibilities for agency and code-exchange in the sense of a "practice of everyday life". (Mörsch, 2009, p. 20)
\end{abstract}

En este sentido, desde el análisis de las voces posibles que intervienen en esta relación, el objeto puede observarse desde una distancia crítica no en un sentido histórico, al contrario, la lectura o las lecturas suceden desde la significación que se le otorga a través del proceso de enmarcarlo, y que lo activa como artefacto cultural, como vínculo dinámico para la reflexión y generación de contenidos y por tanto, de procesos de interpretación, producción de conocimiento y diálogo. 
En el caso del Walkman de Sony intervienen múltiples voces. La mise-en-scène es el objeto mientras que el "enmarcado" son los procesos de producción de significado que se le otorgan al hacerlo parte de la exposición, al presentarlo como objeto cultural, al ubicarlo en la sala junto con las demás piezas sobre el 79 y al insertarlo en una red de vínculos como la práctica cultural que genera su uso (el aislamiento del entorno, la relación entre el espacio público y privado, entre otros), pero el cierre de este proceso de significación, lo realiza el público como potencial agente de producción de estos significados.

Por tanto, en sí mismo, e incluso al nivel de la mera palabra, el «enmarcado» cuestiona el carácter de objeto de los objetos de estudio de las disciplinas culturales. Este cuestionamiento supone reposicionar los objetos como objetos vivos, algo que tiene que ver con la «vida social de las cosas» más que con la hipóstasis de los objetos o con una estrategia retórica de personificación. También sirve para convertir la imagen -y no el texto- en el tipo de objeto cultural más característico, o incluso paradigmático, siempre que entendemos que se trata de un objeto que vive su vida en el presente y que nuestras formas de enmarcarla son siempre provisionales. (Bal, 2009, pp. 181-182)

Entre tanto, así nuestras formas de enmarcado sean provisionales y aunque se trate de la vida del objeto en el presente, la forma en que nos relacionamos con la cultura tiene un estrecho vínculo con las conexiones que hacemos entre el pasado y el presente. Es decir, para comprender la complejidad del mundo visual es imprescindible establecer estas conexiones ya que son las que posibilitan situar la mirada. A través del estudio de la historia comprendemos los aspectos sociales y culturales "que nos proporcionan las localizaciones conceptuales en que ahora nos encontramos [...]. Sin embargo, la historia no es el pasado; es la reconstrucción del pasado" (Freedman, 2006, pp. 73-74).

Dicha reconstrucción permite también afectar la vida de los objetos en el presente, es el ámbito de acción y de repercusión desde el cual los agentes mediadores realizan el enmarcado. Es el terreno de construcción de significado, el momento en que convergen las prácticas culturales que han dado sentido al objeto, con la vida social y cultural que le adjudica un presente con el que debe conectarse. "En vez de ser universal, el arte que continúa siendo valorado a lo largo del tiempo lo es porque es experimentado de nuevas formas por personas diferentes en momentos diferentes" (Freedman, 2006, p. 69).

En estas conexiones radica también la importancia de revisar este objeto en el ámbito de los estudios de la cultura visual, porque a partir de los vínculos, la interpretación y la significación, se promueven procesos cognitivos que convierten las señales visuales en pensamientos con significado.

Tal como sostiene el psicólogo cognitivo Robert Solso, solo podemos comprender el arte visual gracias a la información que hemos almacenado previamente sobre rasgos visuales y significados. Cuando las personas vemos una organización visual, incluso nuestros movimientos oculares inconscientes son dirigidos por la búsqueda de información que nos ayudará a dar sentido al estímulo según nuestro conocimiento previo. (Freedman, 2006, p. 100) 


\section{Referencias}

Alforova, A. (s. f.). There's a Revolution in the Streets with Sony Walkman [entrada de blog]. Recuperado de https:// bit.ly/36CveDI

Bal, M. (2003). El esencialismo visual y el objeto de los estudios visuales. Estudios visuales: ensayo, teoría y crítica de la cultura visual y el arte contemporáneo, 2, 11-50.

Bal, M. (2009). Conceptos viajeros de las humanidades. Una guía de viaje. Murcia: Cendeac.

Barker, E. (ed.). (1999). Contemporary Cultures of Display. New Haven: Yale University Press.

Clifford, J. (1999). Itinerarios Transculturales. Barcelona: Gedisa.

Du Gay, P., Hall, S., Janes, L., Madsen, A., Mackay, H. y Negus, K. (1997). Doing Cultural Studies. The Story of the Sony Walkman. Londres: The Open University - SAGE.

Freedman, K. (2006). Enseñar la cultura visual: currículum, estética y la vida social del arte. Barcelona: Octaedro.

Greenberg, R., Ferguson, B. y Nairne, S. (1996). Thinking about Exhibition. Nueva York: Routledge.

La Virreina Centre de la Imatge. (2011). 1979. Un monumento a instantes radicales [folleto de exposición]. Barcelona.

Mörsch, C. (2009). At a Crossroads of Four Discourses: documenta 12 Gallery Education in Between Affirmation, Reproduction, Deconstruction and Transformation. En C. Mörsch (ed.), Documenta 12 education II. Between Critical Practice and Visitor Services (pp. 9-31). Berlin; Zürich: Diaphanes.

Pollock, G. (2006). Encountering Encounter: an Introduction. En G. Pollock y V. Corby (eds.), Encountering Eva Hesse (pp. 13-23). London-Munich: Prestel.

Snick, P. Van. (2010). Dynamic Project. Bruselas: ASA Publishers. 
Vidal, J. (29 de abril del 2011). 1979, crónica de un tiempo. El Cultural. Recuperado de https://bit.ly/2S5EATo

Villamil, I. (2011). La (des) articulación del mito [entrada de blog]. Recuperado de: https:/ / bit.ly/311AdN8

\section{Anexo}

Folleto de exposición 1979. Un monumento a instantes radicales.

\section{9 \\ UN MONUMENTO A INSTANTES RADICALES}

Entre 1968 y 1989 hay 1979, un año cualquiera. Nada indica, en principio, que esta fecha sea más relevante que otras. Sin embargo, al recopilar algunos de los acontecimientos de aquel año, enseguida emerge una constelación de hechos, obras, datos, textos, imágenes, películas, canciones y objetos que, a pesar de que en un primer momento no parecen compartir más que la fecha, sugieren muy pronto una inflexión histórica. 1979 vio la llegada al poder de Margaret Thatcher. el fin de una década intensa en Italia con el encarcelamiento de figuras como Antonio Negri, dos revoluciones clave, todavia hoy en día, como la de Nicaragua y la de Irán, así como una larga lista de microacontecimientos que algunas fotografías podian haber logrado captar y retener. La exposición se plantea como un ensayo histórico que evita una imagen compacta de aquel año. Por el contrario, busca representar la heterogeneidad de los acontecimientos comprendidos, como si la historia una vez revisada todavia pudiese sugerir una multiplicidad de direcciones y líneas de desarrollo.

Evidentemente, tampoco se trata de una fecha escogida al azar. 1979 es el año que marca un punto de inflexión para e posfordismo, cerrando una década violenta pero rica en la comprensión de las nuevas dinámicas del capitalismo, un lapso de tiempo que, visto desde una perspectiva cultural, estará marcado por la posmodernidad, la forma cultural que Frederic Jameson asoció al tardocapitalismo. 1979 es también el año en que Michel Foucault dicta su curso sobre el nacimiento de la biopolítica, una interrogación sobre los limites de la acción de gobierno que, cada vez más, se acerca al control de la vida. Tampoco es casualidad que aquel sea el año en el que se da inicio en Barcelona a un gobierno local elegido democráticamente y se lleva a cabo una encuesta urbana que fundaría los proyectos futuros de la ciudad. El año, en definiliva, que puede aydarnos a reinterpretar nuestro pasado inmediato sin caer en narrativas precocinadas.

La exposición, que se despliega en los espacios de La Virreina Centre de la Imatge, se articula, entre otros, en torn a materiales documentales como los del archivo de Peter Widerstands (La estética de la resistencia, 1975-1981). Este libro Widerstands (La estética de la resistencia, 1975-1981). Este lib y los materiales de archivo asociados a su génesis constituyen su núcleo. El relato de Peter Weiss sitúa la acción entre 1937 y 945 , transitando de la Guerra Civil española a la Segunda Guerra Mundial. Pero pese a su carácter histórico, desvela las preocupaciones del autor a lo largo de las décadas de 1960 y 1970 , años marcados, en su caso, por el desencanto respeto a la socialdemocracia y por una conciencia cada vez más global en cuanto a los con tictos del mundo. Así pues, da forma a la Guerra Civil española, de la que el escritor sólo tuvo conocimiento a través de documentos históricos. Los cuadernos de ex brigadistas y las visitas del propio Los cuadernos de ex brigadistas y las visitas del propio escritor a los escenarios de los hechos son la fuente de una escritura que adopta un tono documental, rigurosoy La estética de la resistencia se configure como una novela épica, "un monumento literario edificado sobre un mar de documentación", en la que encontramos un gran número de reproducciones de obras de arte, muchas de ellas citad como ejemplos de una pedagogía colectiva y subalterna. Los protagonistas de la novela a menudo contemplan estas obras a través de reproducciones, en un estado de fatiga al final de una larga jornada de trabajo o bajo condiciones de estrés bélico, por lo que su percepción nunca llega a ser completa ni satisfactoria. Por el contrario, la práctica conversacional que se deriva del encuentro con estos iconos de la historia del arte anuncia una nueva forma de consumo cultural. Desde la perspectiva de La estética de la resistencia la interpretación se convertirá en un momento tan productivo, o más, que el de la creación.

Así pues, el núcleo del proyecto está ocupado por los préstamo de la Akademie der Künste de Berlín, donde se encuentran los cuadernos de Peter Weiss, así como por la gran pintura de Robert Koehler titulada La huelga (1886), procedente del Deutsches Historisches Museum Berlin y que el mismo Peter Weiss citaba para ejemplificar una nueva noción de produc tividad basada en los intercambios comunicativos, la nueva fábrica de finales del siglo xx. Desde este punto concreto, el desmantelamiento de la industria clásica del xix y la decadencia urbana que deriva de ello se despligan como hilos argumentales de la exposición, así como las revoluciones y cambios políticos más destacados de aquel año. Los documentales militantes que muestran huelgas y procesos insólitos, como el de la fábrica Numax en Barcelona o el del encierro en los astilleros de Gdansk, en Polonia, revelan nuevas lógicas en las reivindicaciones laborales. Tras la huelga, la clase obrera no tiene ganas, de ningún modo, de volver a la fábrica tradicional, que empieza a parecer obsoleta. Muchos barrios, como el de Poblenou, en Barcelona, conocido como el Manchester catalán, iniciarán un proceso de abandono. El carácter pintoresco que fotógrafos como Juli Azcunce, Manolo Laguillo y Humberto Rivas experimentaban paseando por zonas de la ciudad en transformación, hoy se lee como un testimonio de la terciarización emergente de Barcelona en aquellas fechas.

Otros fotógrafos como Pep Cunties, Eduardo Subias y Jesús Atienza prefirieron documentar instituciones municipales tales como el Hospital Psiquiátrico Pi i Molist, un geriátrico en la Bonanova o el antiguo matadero. La visión de estas tre instituciones a finales de la década de 1970 y principios de 1980 equipara la gestión que se hacía de los cuerpos enfermos o envejecidos con el modo de sacrificar a los animales destinado a la industria de la alimentación. Un aire de familia recorre los tres lugares. Este complejo retrato $-y$ al mismo tiempo denuncia del estado en el que se encuentran instituciones como estas, que parecen operar todavía con los preceptos del siglo xix-, revela un nuevo tipo de poder que, como decía el filósofo francés Michel Foucault, pasa a ocuparse de la vida. Tampoco es casualidad que fuese entonces cuando la cultura comenzo a utilizarse como una arma biopolítica con potencial para corregir situaciones de degradación social. El modelo más logrado en cuanto a este tipo de intervenciones lo representará el Centre Pompidou, un equipamiento de grandes dimensiones que surge en el mismo centro de París en 1977 y que Rossellini filmo con un escepticismo manifiesto. El equivalente en Barcelona será el plan Del Seminari al Liceu, un proyecto de gran alcance y de concentración de equipamientos en el barrio del Raval. El MACBA (Museu d'Art Contemporani de Barcelona) y el CCCB (Centre de Cultura Contemporània) son algunos de los espacios imaginados en aquella fecha.

Pero antes de considerar la instrumentalización de la cultura que se inició durante la década de 1980, hay que entender jóvenes tecnócratas de los últimos años del franquismo y 


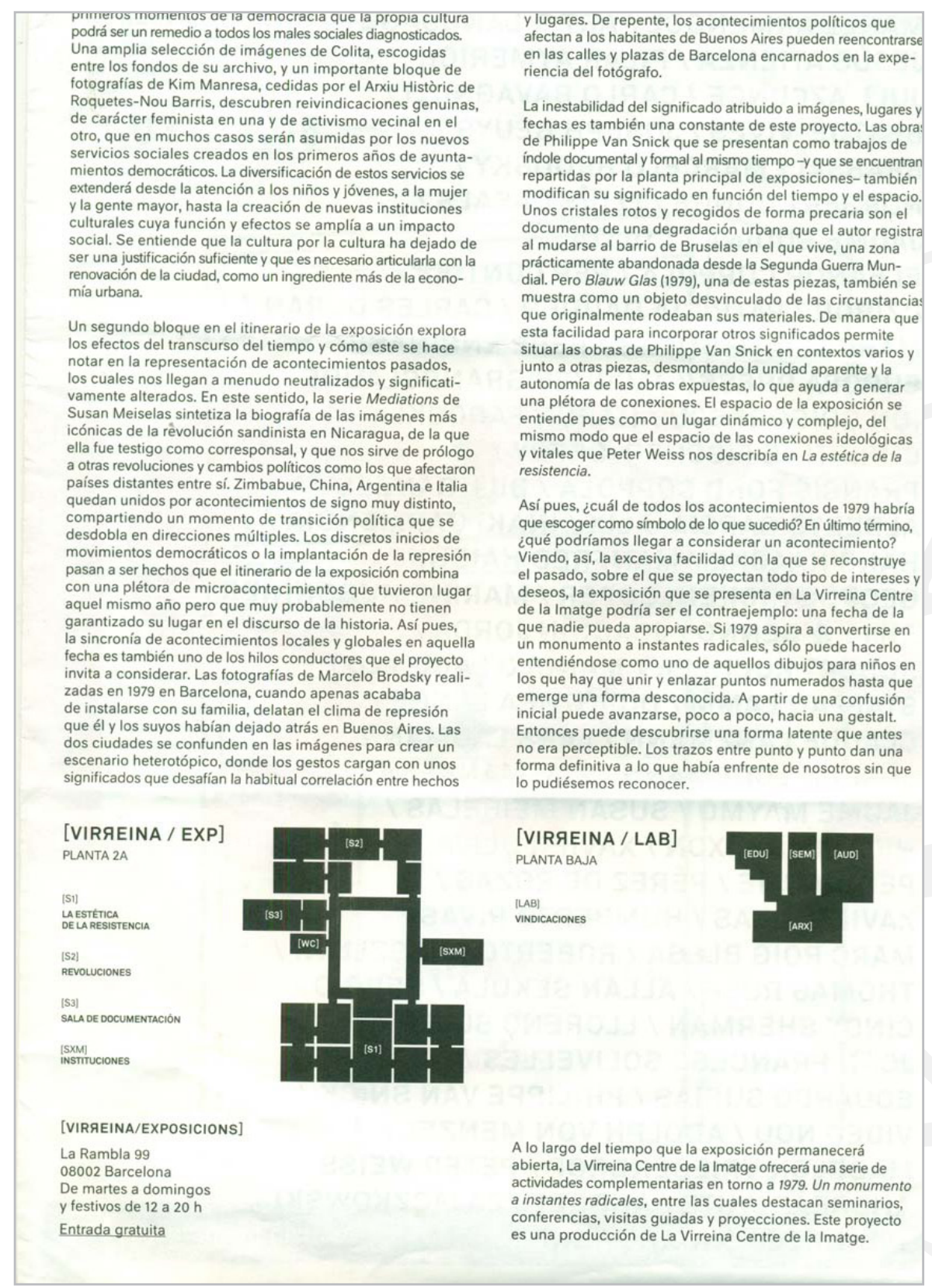

Fuente: La Virreina Centre de la Imatge (2011). 